\title{
Uterine Prostaglandin E Secretion and \\ Uterine Blood Flow in the Pregnant Rabbit
}

\author{
Rocco C. Venuto, Thomas O’Dorisio, Jay H. Stein, and \\ THOMAS F. FerRIS \\ From the Department of Medicine, Ohio State University College of Medicine, \\ Columbus, Ohio 43210
}

\begin{abstract}
A B S T R A C T Studies were performed in pregnant rabbits to assess the effect of inhibition of prostaglandin synthesis on uterine blood flow. Cardiac output and uteroplacental blood flow (UPBF) were measured using radiolabeled microspheres. Prostaglandin $\mathrm{E}$ (PGE) concentration was measured by radioimmunoassay in the uterine vein and peripheral artery of the pregnant nephrectomized rabbit. Either meclofenamate or indomethacin $2 \mathrm{mg} / \mathrm{kg}$ were utilized to inhibit prostaglandin synthesis. Systemic arterial pressure increased from $86 \mathrm{~mm} \mathrm{Hg}$ to $98 \mathrm{~mm} \mathrm{Hg}(P<0.001)$ after prostaglandin inhibition. Cardiac output was unchanged after the inhibition of prostaglandin synthesis, $326 \mathrm{ml} /$ min vs. $340 \mathrm{ml} / \mathrm{min}$, while UPBF fell from $16.5 \mathrm{ml} /$ $\min$ to $7.8 \mathrm{ml} / \mathrm{min}$. Uterine vein $\mathrm{PGE}$ concentration was extremely high, $172.4 \mathrm{ng} / \mathrm{ml}$, with concomitant peripheral arterial PGE $2.1 \mathrm{ng} / \mathrm{ml}$. Intravenous administration of either meclofenamate or indomethacin reduced uterine vein $\mathrm{PGE}$ to $23 \mathrm{ng} / \mathrm{ml}(P<0.01)$ and arterial $P G E$ to $1.0 \mathrm{ng} / \mathrm{ml}(P<0.05)$. Male and nonpregnant female rabbits had lower arterial PGE, 0.37 $\mathrm{ng} / \mathrm{ml}(P<0.05)$. Studies in non-nephrectomized pregnant animals demonstrated that uteroplacental secretion of PGE was greater than five times renal secretion. These studies demonstrate that the rabbit uteroplacental unit is a rich source of PGE and suggest that production of the vasoactive lipid may have a key role in regulating UPBF during pregnancy.
\end{abstract}

\section{INTRODUCTION}

Factors controlling uteroplacental blood flow (UPBF) ${ }^{1}$ are poorly understood. This control system is of special importance since uteroplacental ischemia has been proposed as a factor in the development of toxemia of preg-

Received for publication 4 June 1974 and in revised form 16 September 1974.

${ }^{1}$ Abbreviations used in this paper: PGE, prostaglandin E; UPBF, uteroplacental blood flow. nancy (1). Previous studies performed in this laboratory have demonstrated that the administration of pharmacologic doses of angiotensin were associated with an increase in UPBF without significantly affecting the cardiac output (2). It was suggested that the fall in uterine resistance might be mediated through a locally released vasodilator substance. A similar fall in uterine vascular resistance induced by angiotensin infusion and thought to be mediated via prostaglandin synthesis has been reported in the dog by Terragno, Terragno, $\mathrm{Pa}$ cholczyk, and McGiff (3). Recent studies in humans and rabbits have demonstrated the uterus and placenta to be rich sources of several prostaglandins including those of the $E$ series (PGE) (4-6). This series of prostaglandins have potent vasodilatory effects and have been demonstrated to increase blood flow when injected directly into a uterine artery $(7,8)$. However, the results obtained by the infusion of the vasodilator into the uterine arterial circulation do not necessarily imply a relationship to a physiologic control system. This is especially pertinent in evaluating prostaglandins of the $E$ series since they are rapidly metabolized in the lung (9) and are presumed to act primarily at the local site of production. Thus, the evaluation of the physiologic role of prostaglandin on UPBF could best be accomplished by means which either increase or decrease synthesis of the vasoactive substance at the tissue level. This latter maneuver can be carried out by the administration of a number of anti-inflammatory agents which have been shown to inhibit the enzyme, prostaglandin synthetase (10). Using the pregnant rabbit as the experimental model, this study clearly demonstrates that inhibition of prostaglandin synthesis is associated with profound uterine ischemia.

\section{METHODS}

Experiments were performed in $3.5-5-\mathrm{kg}$ New Zealand white rabbits studied between the 23rd and 29th day of gestation and prepared by methods previously described (2). $24 \mathrm{~h}$ 
before the experiment a bilateral nephrectomy was carried out and the animals were kept without food or water. In all experiments the animals were anesthetized with pentobarbitol, then a tracheostomy and catheterization of the left jugular vein and the right carotid artery were performed. The carotid catheter was advanced until a left ventricular pressure tracing was recorded. An additional catheter was placed in the right femoral artery for monitoring blood pressure and drawing blood samples, and the uterine veins were exposed through a lower midline abdominal incision.

Cardiac outputs and UPBFs were determined using radioactive microspheres $15 \pm 5-\mu \mathrm{m}$ diameter labeled with ${ }^{85} \mathrm{Sr}$ or ${ }^{141} \mathrm{Ce}$ (3M Company, St. Paul, Minn.). A $0.2-\mathrm{ml}$ solution containing approximately 500,000 microspheres was diluted with $10 \%$ dextran to a volume of $2.0 \mathrm{ml}$ and carefully mixed. One-fourth of the volume was retained as a standard while the remaining $1.5 \mathrm{ml}$ was injected through the left ventricular catheter, followed by a rapid irrigation of the catheter with $5 \mathrm{ml}$ of isotonic saline. This process was performed over $20 \mathrm{~s}$. Simultaneously blood was withdrawn from the right femoral artery with a Harvard infusion pump (Harvard Apparatus Co. Inc., Millis, Mass.) at a rate of $5 \mathrm{ml}$ per min over a 1-min interval.

After the animals had stabilized an initial injection of microspheres was given. Then either meclofenamate (Parke, Davis and Co., Detroit, Mich.), $2 \mathrm{mg} / \mathrm{kg}$ (six studies) or indomethacin (Merck, Sharp \& Dohme, West Point, Pa.) $2 \mathrm{mg} / \mathrm{kg}$ (four studies) were given i.v. $30 \mathrm{~min}$ after the administration of the prostaglandin inhibitor, a second sphere was given and appropriate blood samples collected.

At the completion of the experiment, the uterus and placentae were removed, weighed, and digested in concentrated $\mathrm{HCl}$. The digested volume was measured and aliquots were counted, along with reference femoral samples and the remaining $0.5 \mathrm{ml}$ of the injectate, in a Packard autogamma counter (Packard Instrument Co. Inc., Downers Grove, Ill.). ${ }^{85} \mathrm{Sr}$ was counted at the $0.510 \mathrm{MeV}$ peak and the ${ }^{111} \mathrm{Ce}$ at the $0.45 \mathrm{MeV}$ peak. No correction was necessary for the ${ }^{85} \mathrm{Sr}$ counts but $7 \%$ of the ${ }^{85} \mathrm{Sr}$ counts were subtracted to obtain the true ${ }^{141} \mathrm{Ce}$ counts in the tissues.

Two other groups of experiments were performed. In four studies, pregnant rabbits were prepared as described except nephrectomy was not done. Uterine, renal venous, and peripheral arterial PGE levels were obtained. Renal vein samples were collected by a direct puncture with a 23-gauge needle. In 11 additional rabbits, 6 males and 5 nonpregnant females, peripheral arterial blood was collected for PGE after the animal had been anesthetized and stabilized.

Plasma prostaglandin was measured by radioimmunoassay using a modification of the method described by Zusman and associates (11). Blood was collected in heparinized tubes to which indomethacin 50-70 $\mathrm{gg}$ had been added. Plasma was acidified to $\mathrm{pH} 3.7$ with citric acid and $1 \mathrm{ml}$ was placed in an extraction tube to which $\left[{ }^{3} \mathrm{H}\right] \mathrm{PGE}_{2}(1,000$ cpm) was added. The plasma was extracted twice with ethyl acetate and the extract dried under air before application on a silicic acid column. The columns were prepared using $0.5 \mathrm{~g}$ silicic acid (100 mesh, Mallinckrodt Chemical Works, St. Louis, Mo.) slurried with $60: 40: 2$, benzene: ethyl acetate: methanol. Dried extracts were dissolved in 0.2 $\mathrm{ml}$ solvent $(60: 40: 10)$ and a total of $0.8 \mathrm{ml} 60: 40(0.6$ $+0.2)$ applied to the column. When this solvent was completely eluted, $1 \mathrm{ml}$ benzene was added to the column and also allowed to run dry. $4 \mathrm{ml} \mathrm{60:40} \mathrm{solvent} \mathrm{is} \mathrm{added} \mathrm{and}$ this fraction, which contains approximately $90 \%$ of added PGA, is run to dryness. $13 \mathrm{ml}$ of $60: 40: 2$ is then added to the column and the eluates collected in scintillation tubes. Recovery of tracer $\mathrm{PGE}_{2}$ added to the 28 rabbit plasmas in these experiments was $70.4 \pm 7$ SEM\%.

The antiserum used for the immunoassay was prepared against $\mathrm{PGE}_{1}$ at the Worcester Foundation for Experimental Biology, Shrewsbury,Mass. (Stylos, Howard, Ritzi, and Skarnes [12]). This antiserum exhibits a $22 \%$ cross reactivity with $P G E_{2}$ but no cross reaction with 15-keto $\mathrm{PGE}_{1}$, 15-keto dihydro $P \mathrm{GE}_{1}$ or $\mathrm{PGB}_{1}$. When $\mathrm{PGA}_{1}$ and $P G E_{1}$, in equivalent amounts, are added to the assay system appreciable displacement of $\left[{ }^{8} \mathrm{H}\right] \mathrm{PGE}_{1}$ occurs. Prior column chromatography, however, removes $90-95 \%$ of added $\mathrm{PGA}_{1}$. When we added $\mathrm{PGA}_{2}$ to rabbit plasma in concentrations from $5 \mathrm{ng}$ to $100 \mathrm{ng}$, only $5 \%$ of the PGA was measured as PGE. Thus, utilizing both column and antiserum, one can separate PGA from PGE but cannot accurately distinguish between $\mathrm{PGE}_{1}$ and $\mathrm{PGE}_{2}$. Thus, all values in the paper are expressed as PGE.

Immunoassay. $\left[{ }^{3} \mathrm{H}\right] \mathrm{PGE}_{2}$ (New England Nuclear, Boston, Mass.) is chromotographed twice on the silicic acid column and diluted in phosphate buffer $(0.15 \mathrm{M} \mathrm{NaCl}$, $0.01 \mathrm{M}$ phosphate, $\mathrm{pH} 7.0$ ) to $10,000 \mathrm{cpm} / 0.1 \mathrm{ml}$. A small amount of $\left[{ }^{3} \mathrm{H}\right] \mathrm{PGE}_{2}$ is dissolved in ethanol to provide 1,000 $\mathrm{cpm} / 0.1 \mathrm{ml}$ and this is added to each sample to determine percent recovery. All samples are done in duplicate. Dilution of the antiserum is carried out to provide $50 \%$ binding of the $\left[{ }^{3} \mathrm{H}\right] \mathrm{PGE}_{2}$. $1 \mathrm{ml}$ ethanol is added to each dried plasma sample and $0.1 \mathrm{ml}$ and $0.2 \mathrm{ml}$ aliquots are placed in $12 \times 75-\mathrm{mm}$ culture tubes and dried. The remaining 0.7 $\mathrm{ml}$ is dried and used for the recovery determination. $1 \mathrm{ml}$ buffer, $0.1 \mathrm{ml}\left[{ }^{3} \mathrm{H}\right] \mathrm{PGE}_{2}$ (containing $10,000 \mathrm{cpm}$ ) and 0.1 $\mathrm{ml}$ antiserum are added to the $12 \times 75-\mathrm{mm}$ tubes and incubated $3 \mathrm{~h}$ at $4^{\circ} \mathrm{C}(1 \mathrm{ml}$ dextran-coated charcoal solution is then added, and the tubes are then centrifuged) at 5,000 $\mathrm{rpm}$ for $20 \mathrm{~min}$. Standards of cold $\mathrm{PGE}_{2}$ are incubated in similar fashion and determination of displacement of $\left[{ }^{3} \mathrm{H}\right]-$ $\mathrm{PGE}_{2}$ from the antiserum determined in the usual fashion.

The reproducibility of the assay in rabbit plasma with a mean PGE concentration of $3.53 \mathrm{ng} / \mathrm{ml}$ in replicate fashion 10 times showed a variance of $0.24 \mathrm{ng} / \mathrm{ml}$. When $\mathrm{PGE}_{2}$ was added to pooled rabbit plasma in concentrations ranging from $0.25 \mathrm{ng}$ to $10 \mathrm{ng}$, the percent recovery was $105 \pm 7 \%$. The addition of $1-1,000 \mathrm{ng}$ of either $\mathrm{PGE}_{22}$ or $\mathrm{PGA}_{2}$ yielded crossovers of less than $1 \%$ in the case of $\mathrm{PGF}_{2 \mathrm{n}}$ and up to $7 \%$ in the case of $\mathrm{PGA}_{1}$. Measurements of peripheral PGA levels were $90 \%$ and uterine venous PGA concentration $3 \%$ of simultaneously drawn PGE $(n=10)$. Thus, the contribution of PGA to the measured PGE level was $6 \%$ and less than $1 \%$ in peripheral and uterine venous blood, respectively.

Calculations. The cardiac output and UPBF were determined by a modified indicator dilution technique. The following calculations were used :

\section{Cardiac output $(\mathrm{ml} / \mathrm{min})$}

cpm injected

$$
=\frac{\text { Blood withdrawal rate }(\mathrm{ml} / \mathrm{min})}{\text { Total } \mathrm{cpm} \text { in blood }},
$$

Uterine blood flow ( $\mathrm{ml} / \mathrm{min})$

Total cpm in uterus

$$
=\frac{\text { Blood withdrawal rate }(\mathrm{ml} / \mathrm{min})}{\text { Total } \mathrm{cpm} \text { in blood }},
$$


TABLE I

Effect of Prostaglandin Inhibition on Uterine Blood Flow and Prostaglandin Levels

\begin{tabular}{|c|c|c|c|c|c|c|c|c|c|c|c|c|}
\hline \multirow{2}{*}{$\begin{array}{l}\text { Exp. } \\
\text { no. }\end{array}$} & \multicolumn{2}{|c|}{$\begin{array}{l}\text { Cardiac } \\
\text { output }\end{array}$} & \multicolumn{2}{|c|}{ UPBF } & \multicolumn{2}{|c|}{$\begin{array}{l}\text { Fractional } \\
\text { UPBF }\end{array}$} & \multicolumn{2}{|c|}{$\begin{array}{l}\text { Uterine } \\
\text { PGE }\end{array}$} & \multicolumn{2}{|c|}{$\begin{array}{l}\text { Peripheral } \\
\text { PGE }\end{array}$} & \multicolumn{2}{|c|}{$\begin{array}{l}\text { Mean arterial } \\
\text { pressure }\end{array}$} \\
\hline & Cont & Exp & Cont & Exp & Cont & Exp & Cont & Exp & Cont & Exp & Cont & Exp \\
\hline & \multicolumn{2}{|c|}{$\mathrm{cm}^{3} / \min$} & \multicolumn{2}{|c|}{$\mathrm{cm}^{2} / \min$} & \multicolumn{2}{|c|}{$\%$} & \multicolumn{2}{|c|}{$n g / m l$} & \multicolumn{2}{|c|}{$n g / m l$} & \multicolumn{2}{|c|}{$m m \mathrm{Hg}$} \\
\hline 1 & 191.5 & 240.5 & 14.0 & 6.8 & 7.0 & 3.0 & 45.3 & 4.8 & 1.2 & 0.6 & 79 & 90 \\
\hline 2 & 267.0 & 650.0 & 7.4 & 5.7 & 2.8 & 0.9 & 111 & 6.9 & 2.1 & 1.1 & 119 & 120 \\
\hline 3 & 584.7 & 324.8 & 27.7 & 11.9 & 4.7 & 3.6 & 300 & 34.0 & 4.0 & 1.4 & 90 & 97 \\
\hline 4 & 520.0 & 533.0 & 21.8 & 13.2 & 4.2 & 2.5 & 106 & 6.6 & 1.1 & 1.8 & 81 & 98 \\
\hline 5 & 265.3 & 222.9 & 11.3 & 5.7 & 4.2 & 2.5 & 80.3 & 11.9 & 2.6 & 1.4 & 80 & 83 \\
\hline 6 & 370.7 & 350.0 & 41.4 & 14.0 & 11.2 & 4.0 & 118 & 12.1 & 2.0 & 1.2 & 100 & 120 \\
\hline 7 & 172.0 & 206.8 & 7.7 & 5.0 & 4.5 & 2.4 & 290 & 107 & 4.8 & 0.9 & 78 & 91 \\
\hline 8 & 440.0 & 480.0 & 11.0 & 8.4 & 2.5 & 1.8 & 132 & 4.9 & 1.1 & 0.5 & 90 & 100 \\
\hline 9 & 209.0 & 133.7 & 7.6 & 1.4 & 3.6 & 1.0 & 41.1 & 23.4 & 0.7 & 0.9 & 56 & 67 \\
\hline 10 & 244.1 & 259.3 & 15.0 & 5.8 & 6.2 & 2.2 & 500 & 18.4 & 1.4 & 0.6 & 90 & 118 \\
\hline Mean & 326.4 & 340.1 & 16.5 & 7.8 & 5.1 & 2.4 & 172.4 & 23.0 & 2.10 & 1.04 & 85.9 & 98.4 \\
\hline $\mathrm{SE}$ & 45.8 & 52.1 & 3.5 & 1.3 & 0.8 & 0.3 & 48.3 & 9.8 & 0.42 & 0.13 & 5 & 5 \\
\hline$P$ & \multicolumn{2}{|c|}{ NS } & \multicolumn{2}{|c|}{$<0.01$} & \multicolumn{2}{|c|}{$<0.01$} & \multicolumn{2}{|c|}{$<0.01$} & \multicolumn{2}{|c|}{$<0.05$} & \multicolumn{2}{|c|}{$<0.001$} \\
\hline
\end{tabular}

where cpm is counts per minute of the appropriate sample Results are expressed as mean \pm SE. Statistical analysis of the data was carried out by standard techniques.

\section{RESULTS}

The results of the 10 studies in pregnant rabbits are shown in Table I. No difference was found between the meclofenamate and indomethacin studies; therefore, they have been combined. Mean arterial pressure rose in each study with a mean change from 86 to 98 $\mathrm{mm} \mathrm{Hg}, 30 \mathrm{~min}$ after administration of the anti-inflammatory drugs $(P<0.001)$. Cardiac output was unchanged at $326 \mathrm{ml} / \mathrm{min}$ in the control period and 340 $\mathrm{ml} / \mathrm{min}$ after prostaglandin inhibition. Total UPBF fell in each study with a mean change from 16.5-7.8 $\mathrm{ml} / \mathrm{min}(P<0.01)$. Additionally, the uteroplacental fraction of cardiac output decreased from 5.1 to $2.4 \%$. Uterine venous PGE was extremely high in the control period and averaged $172 \mathrm{ng} / \mathrm{ml}$. After meclofenamate or indomethacin, there was an eightfold decrease in PGE level to $23 \mathrm{ng} / \mathrm{ml}$. Since total UPBF decreased $53 \%$ concomitantly, these findings indicate a striking fall in PGE release from the uteroplacental unit. The peripheral PGE level was $2.1 \mathrm{ng} / \mathrm{ml}$ and fell to 1.04 $\mathrm{ng} / \mathrm{ml}$ in the experimental period $(P<0.05)$.

Fig. 1 compares the peripheral PGE levels in pregnant females, nonpregnant females, and males. With the exception of one study, the peripheral PGE levels were markedly higher in the pregnant rabbits than in either males or nonpregnant females. There was no difference between the latter two groups. In four pregnant rabbits, mean uterine venous, renal venous, and peripheral arterial PGE levels were 256 $\pm 22,5.8 \pm 0.35$, and $1.7 \pm 0.09 \mathrm{ng} / \mathrm{ml}$, respectively.

\section{DISCUSSION}

In the present study, UPBF was measured with a modification of the radioactive microsphere technique before and after the administration of two structurally different anti-inflammatory agents, meclofenamate and indomethacin. The validity and reproducibility of this method of measuring UPBF has been previously demonstrated (2). Using this technique it was clearly shown that both agents caused a marked fall in UPBF without alteration in cardiac output. In each instance mean arterial pressure was also increased to a modest extent. Although some other parameters could have been altered by meclofenamate and indomethacin, the one known common characteristic of these two structurally dissimilar anti-inflammatory agents is inhibition of prostaglandin synthesis (10). This is directly shown in the data in Table I. In each of the 10 studies, uterine venous and peripheral PGE's fell concomitantly after administration of either agent. Thus, these results strongly suggest that in the pregnant rabbit inhibition of prostaglandin synthesis is associated with a marked fall in UPBF.

As shown in Table $I$, the uterine vein PGE levels were extremely high. Although there was considerable variation in the absolute values between studies, the uterine venous: peripheral PGE ratio was at least $30: 1$ in each study, with a mean ratio of $90: 1$. In contrast, renal venous: peripheral $P G E$ ratios averaged 3.4 in four additional studies. Since absolute renal blood flow is only fivefold greater than uteroplacental flow in the pregnant rabbit (2), PGE production is considerably greater in the uterus than in the kidney during pregnancy. In addition, as is shown in Fig. 1, the peripheral 


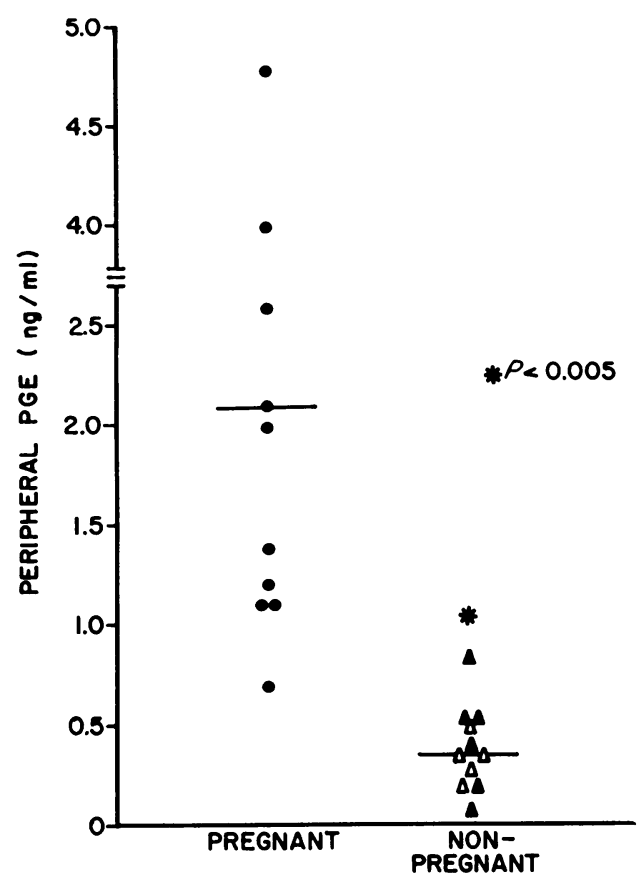

FIGURE 1 Comparison of arterial PGE in pregnant and nonpregnant rabbits. $\Delta$ represent males, $\Delta$ represent nonpregnant females, and $\bullet$ represent pregnant animals.

PGE level is much higher in the pregnant rabbit than in either the male or nonpregnant female rabbit. Because of the vestigal size and low blood flow of the nonpregnant uterus, uterine venous PGE's could not be obtained in the nonpregnant rabbit. However, since there was no difference in the peripheral PGE levels between this group and the male rabbits, it seems unlikely that substantial quantities of PGE were produced by the uterus of the nonpregnant female. Thus, these data suggest that the uterus of the pregnant rabbit is a rich source of PGE production and probably accounts for the sixfold elevation in peripheral PGE level in the rabbit during pregnancy. However, no information is presently available concerning the enzymatic degradation of PGE by the lung in pregnancy.

The crossover studies demonstrated that the PGE determination was not significantly contaminated by a member of the PGA series. Although the crossover of PGA into the PGE assay was as high as $7 \%$, the uterine venous PGA level was approximately $6 \mathrm{ng} / \mathrm{ml}$, a value only $3 \%$ of the PGE level. Thus, the overestimation of $\mathrm{PGE}$ concentrations in uterine venous blood due to PGA is trivial. PGF levels were not obtained in uterine venous blood. However, since the crossover was less than $1 \%$, it is extremely unlikely that the uterine or peripheral PGE levels could be significantly affected by changes in PGF.
The manner in which a decrease in prostaglandin synthesis increases uterine vascular resistance is not clear. In previous studies evaluating the renal circulation, Lonigro, Itskovitz, Crowshaw, and McGiff and Kirschenbaum, White, Stein, and Ferris, both noted a decrease in renal blood flow after the administration of meclofenamate or indomethacin $(13,14)$. In addition, in the former study, there was a profound fall in renal venous $\mathrm{PGE}$ levels as measured by bioassay techniques. It is not clear, however, whether the decrease in both uterine and renal blood flow after prostaglandin inhibition is due directly to decreased release of the vasodilator at the tissue level or to a more complex mechanism. In a number of studies it has been shown that the administration of prostaglandins attenuates the vasoconstrictor effects of norepinephrine and angiotensin while prostaglandin inhibition increases the sensitivity to both agents $(15,16)$. Thus, it is possible that the decrease in UPBF noted in the present work was due to an increased sensitivity to a normal concentration of a vasoconstrictor substance rather than to prostaglandin depletion, per se.

Thus, these studies demonstrate that the pregnant uterus has a tremendous capacity to synthesize and release $\mathrm{PGE}$ and that inhibition of prostaglandin synthetase causes marked fall in UPBF. It would seem likely, therefore, that the local synthesis and release of PGE was intimately involved in the well-known adaptive increase in UPBF which occurs during pregnancy. In addition, since uterine ischemia has been linked with toxemia, it is tempting to speculate that alterations in PGE production could occur in this clinical state. As mentioned previously, prostaglandin deficiency is associated with an increased sensitivity to vasoconstrictor agents. Thus, if a decrease in prostaglandin synthesis is operative in patients with toxemia, one would expect an increased responsiveness to both norepinephrine and angiotensin II. Recent studies have clearly shown this to be the case in women with toxemia of pregnancy $(17,18)$.

\section{ACKNOWLEDGMENTS}

The authors would like to express their appreciation for the expert technical assistance of Freda Giblin.

This work was supported in part by National Institutes of Health grants 5 T01 HL05975-0251, 5 R01 AM13524-06, and 2 R01 HL13653-04, and by grants from the Central Ohio Heart Association.

\section{REFERENCES}

1. Speroff, L. 1973. Toxemia of pregnancy. Mechanism and therapeutic management. Am. J. Cardiol. 32: 582586.

2. Ferris, T. F., J. H. Stein, and J. Kaufmann. 1972. Uterine blood flow and uterine renin secretion. J. Clin. Invest. 51 : 2827-2833. 
3. Terragno, N. A., D. A. Terragno, D. Pacholczyk, and J. C. McGiff. 1974. Prostaglandins and the regulation of uterine blood flow in pregnancy. Nature (Lond.). 249: $57-58$.

4. Ramwell, P. W., and J. E. Shaw. 1970. Biological significance of the prostaglandins. Recent Prog. Horm. Res. 26: 139-187.

5. Karim, S. M. 1967. The identification of prostaglandin in human umbilical cord. Brit. J. Pharmacol. Chemother. $29:$ 230-237.

6. Pickles, V. R., W. J. Hall, F. A. Best, and G. N. Smith. 1965. Prostaglandins in the endometrium and menstrual fluid from normal and dysmenorrheic subjects. J. Obstet. Gynecol. Br. Commonze. 72: 185-192.

7. Lee, J. B. 1968. Cardiovascular implications of the renal prostaglandins. Prostaglandin Symposium of the Worchester Foundation. P. W. Ramwell and J. E. Shaw, editors. Interscience Pubs., Inc., John Wiley and Sons, Inc., New York. 131-146.

8. Clark, K. E., M. J. Ryan, and M. J. Brody. 1973 Effects of prostaglandin $E_{1}$ and $E_{2}$ on uterine hemodynamics and motility. Adv. Biosci. 15: 779-782.

9. McGiff, J. C., N. A. Terragno, J. C. Strand, J. B. Lee, and A. J. Lonigro. 1969. Selective passage of prostaglandins across the lung. Nature (Lond.). 223: 742745.

10. Vane, J. R. 1971. Inhibition of prostaglandin synthesis as a mechanism of action for aspirin-like drugs. Nat. New Biol. 231 : 232-235.

11. Zusman, R. M., D. Spector, B. V. Caldwell, L. Speroff,
G. Schneider, and P. J. Mulrow. 1973. The effect of chronic sodium loading and sodium restriction on plasma prostaglandin $\mathrm{A}, \mathrm{E}$, and $\mathrm{F}$ concentrations in normal humans. J. Clin. Invest. 52: 1093-1098.

12. Stylos, W., L. Howard, E. Ritzi, and R. Skarnes. 1974. The preparation and characterization of prostaglandin $\mathrm{E}_{1}$ antiserum. Prostaglandins. 6: 1-13.

13. Lonigro, A. M., H. D. Itskovitz, K. Crowshaw, and J. C. McGiff. 1973. Dependency of renal blood flow on prostaglandin synthesis in the dog. Circ. Res. 32: 712717.

14. Kirschenbaum, M., N. White, J. H. Stein, and T. F. Ferris. 1974. Redistribution of renal cortical blood flow during inhibition of prostaglandin synthesis. $\mathrm{Am}$. J. Physiol. 227 : 801-805.

15. Aiken, J. W., and J. R. Vane. 1973. Intrarenal prostaglandin release attenuates the renal vasoconstrictor activity of angiotensin. J. Pharmacol. Exp. Ther. 184: 678-687.

16. Kadowitz, P. J. 1972. Effect of prostaglandins $E_{1}, E_{2}$, and $A_{2}$ on vascular resistance and responses to noradrenaline, nerve stimulation, and angiotensin in the dog hindlimb. Br. J. Pharmacol. 46 : 395-400.

17. Talledo, O. E., L. C. Chesley, and F. P. Zuspan. 1968. Renin-angiotensin system in normal and toxemic pregnancies. Am. J. Obstet. Gynecol. 100: 218-221.

18. Gant, N. F., G. L. Daley, S. Chand, P. J. Whalley, and P. C. MacDonald. 1973. A study of angiotensin II pressor response throughout primigravid pregnancy. $J$. Clin. Invest. 52 : 2682-2689. 